\title{
As disciplinas de didática em cursos de pedagogia no Brasil e a ocorrência da temática biblioteca escolar: um estudo bibliométrico das influências bibliográficas
}

\author{
Didactic in the disciplines of pedagogy courses in Brazil and the occurrence of thematic \\ school library: a bibliometric study of the bibliographic influences
}

João Melo Maricato

Doutor em Ciência da Informação pela Universidade de São Paulo - USP. Professor Adjunto do Curso de Biblioteconomia da Universidade Federal de Goiás - UFG. E-mail: jmmaricato@gmail.com

\begin{abstract}
Andrea Pereira Santos
Doutorado em Geografia Humana pela Universidade Federal de Goiás - UFG. Professora Adjunta do Curso de Biblioteconomia da Universidade Federal de Goiás - UFG.

E-mail: andreabiblio@gmail.com

Raidan Cruz Silveira Bacharel em Biblioteconomia pela Universidade Federal de Goiás - UFG. E-mail: raidan_hb@hotmail.com
\end{abstract}

\section{Resumo}

Objetiva-se conhecer as influências bibliográficas nas disciplinas de didática em cursos de Pedagogia no Brasil e a ocorrência da temática biblioteca escolar. Trata-se de um estudo bibliométrico das referências/citações aplicado aos planos de ensino. Na metodologia selecionamos um Corpus composto por 29 universidades: (6) da região norte, (8) da região nordeste, (4) da região centro-oeste (7) da região sudeste e (4) da região sul. Com a caracterização das disciplinas de didática foram identificados publicações e autores mais citados. Constatou-se, por meio da análise dos sumários e índices das publicações e pela leitura técnica dos 19 livros mais influentes, que nenhuma apresenta ou discute a temática biblioteca escolar de maneira substancial. Pode-se afirmar que a compreensão da biblioteca escolar como instrumento pedagógico não está concreta para os estudiosos da área de didática. Porém, é relevante reafirmar o potencial pedagógico da biblioteca escolar na trajetória escolar do aluno, principalmente àqueles inseridos nas séries iniciais.

Palavras-chave: Pedagogia. Didática. Biblioteca escolar. Bibliometria. Bibliografias.

\begin{abstract}
It aims to know the influences of didactic literature in the disciplines of pedagogy courses in Brazil and the occurrence of theme of school library. The research can be classified as a bibliometric study of references / citations applied to discipline's programs. The population consists of 29 universities: (6) in the Northern region, (8) of the Northeastern region, (4) the Midwest (7) and the Southeast (4) in the South. With the characterization of subjects were identified didactic publications and authors cited. It was found through the analysis of indexes and abstracts of the publications and for the technical reading of the 19 most influential books, presents the theme that no school library substantially. It can be stated that the understanding of the school library as an educational tool is not practical for researchers in the area of teaching. However, it is important to reaffirm the teaching potential of the school library in the school life of the student, especially those entered in the initial series.
\end{abstract}

Keywords: Pedagogy. Didactic. School library. Bibliometrics. Bibliographies. 
As disciplinas de didática em cursos de pedagogia no Brasil e a ocorrência da temática biblioteca escolar: um estudo bibliométrico das influências bibliográficas

\section{Introdução}

A presente pesquisa caracteriza as disciplinas de didática em cursos de pedagogia no Brasil a fim de conhecer os autores e obras mais influentes e compreender se, e como, a temática biblioteca escolar está presente nos planos curriculares dos cursos. Para isso, são utilizados os métodos bibliométricos que, segundo Bufrem e Prates (2005), estão relacionados ao entendimento e estudo dos processos de produção, disseminação e uso da informação. Tais métodos têm sido aplicados com os mais diversos objetivos e disciplinas, trazendo informações ricas e novas possiblidades de compreensão sobre os objetos analisados.

Na presente pesquisa, damos ênfase aos cursos de licenciatura em Pedagogia e suas disciplinas de didática por serem intrinsecamente ligadas às relações de ensino-aprendizagem. Mesmo que as disciplinas de didática não sejam as únicas a manter tais relações, existe certo consenso que as similiaridades são marcantes nas disciplinas de didática.

Além de oferecer caracterização ampla dos autores influentes/citados nos cursos de pedagogia no Brasil, a pesquisa parte do pressuposto de que, a biblioteca escolar consiste em um ambiente condutor para a formação do estudante, devendo ser considerada e inserida no contexto do processo de ensino-aprendizagem. Assim, busca compreender se a temática está presente nas bibliográfias desses cursos no cenário brasileiro.

Levando em consideração que o objetivo principal da didática está focado no processo de ensino-aprendizagem e que, uma das formas de adquirir conhecimento se dá por meio da busca de informações, a biblioteca escolar representa uma das ferramentas na qual o estudante pode desenvolver sua formação cognitiva. Para que isto ocorra, a biblioteca escolar, necessariamente, deve ser vista como instrumento pedagógico, devendo figurar, portanto, no conteúdo curricular dos cursos de pedagogia.

Para que a biblioteca escolar funcione, efetivamente, como um instrumento pedagógico, é necessário que possua excelência (boa estrutura física, acervo, profissionais capacitados, etc). É fundamental, também, a ação e integração entre o bibliotecário e o corpo docente da escola. Dentre eles, entendemos que o papel do pedagogo se destaca, pois possui potencial natural para inserir a biblioteca escolar no rol dos instrumentos de ensinoaprendizagem. Diante dessa perspectiva, entende-se que o tema biblioteca escolar deve fazer parte da formação do pedagogo. 
João Melo Maricato, Andrea Pereira Santos e Raidan Cruz Silveira

Com o exposto, a pesquisa procura, em primeiro lugar, caracterizar as disciplinas de didática dos cursos de pedagogia do Brasil por meio da análise das bibliografias básicas e complementares existentes nos planos de ensino. Em segundo lugar, busca compreender se a temática biblioteca escolar vem sendo abordada nesses cursos a partir das referências. Para isso, são analisados os sumários e índices das obras mais influentes (citadas nos planos de ensino) e realizada a leitura técnica dessas obras. A partir dessas análises, torna-se possível inferir se a temática tem sido considerada na formação dos pedagogos no Brasil.

\section{Metodologia e Procedimentos Metodológicos}

O método utilizado na pesquisa foi o estudo bibliométrico, tendo em vista que a análise se deu a partir das referências/citações dos planos de ensino das disciplinas de didática. Além da construção e análise de indicadores quantitativos, as principais referências identificadas foram analisadas qualitativamente, visando à identificação de temas relacionados à biblioteca escolar. Apesar do caráter fortemente descritivo e quantitativo, buscou-se contextualizar os indicadores observados.

As universidades com curso(s) de pedagogia na modalidade licenciatura, selecionadas totalizaram 29. Chegou-se a esse número depois de feitas pesquisas nos sites de todas as instituições de ensino superior Federais do Brasil no ano de 2012 que ofereciam o curso de licenciatura em pedagogia. Todas as 5 regiões brasileiras foram representadas: 6 universidades da região norte, 8 da região nordeste, 4 da região centro-oeste, 7 da região sudeste e 4 da região sul. O Mapa 1 ilustra as universidades brasileiras com cursos de graduação em pedagogia que fizeram parte do corpus da pesquisa. 
As disciplinas de didática em cursos de pedagogia no Brasil e a ocorrência da temática biblioteca escolar: um estudo bibliométrico das influências bibliográficas

\section{Mapa 1 - Universidades brasileiras que tiveram planos de ensino dos cursos de pedagogia estudados - Corpus da pesquisa}

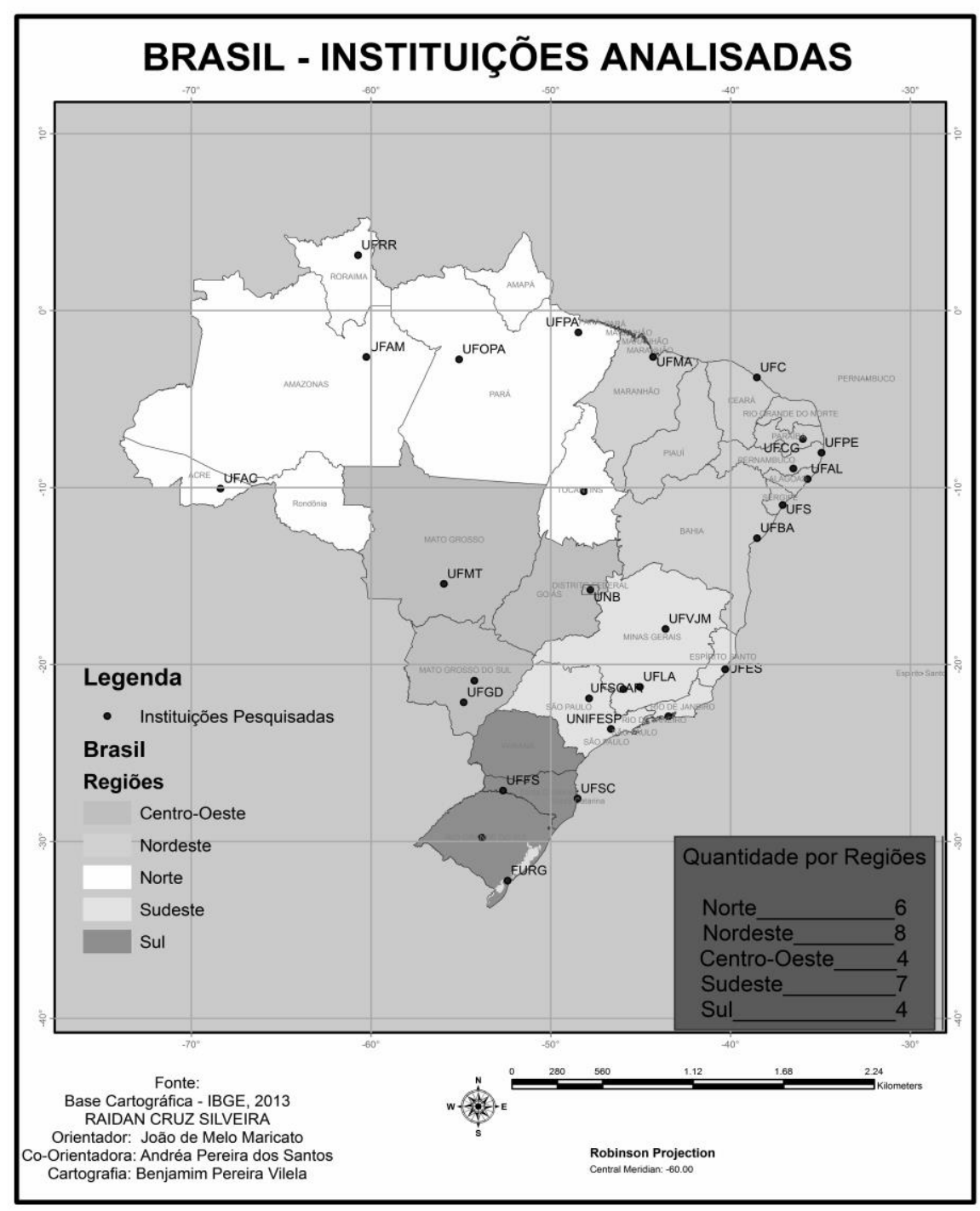

Fonte: Dados da pesquisa elaborado pelos autores, 2012

Após a delimitação das universidades participantes, buscou-se os documentos com as referências (bibliografias básicas e complementares) das disciplinas de didática das universidades. Um dos documentos que atesta com clareza essas informações bibliográficas denomina-se plano de ensino (ou plano curricular). Segundo Menegolla e Sant'Anna (2002, p. $68^{1}$ apud BRAMBILLA; STUMPF, 2005, p. 40) os planos de ensino "compreendem os planos de disciplinas, de unidades, de aulas e de outras atividades ou experiências de ensino”.

\footnotetext{
${ }^{1}$ MENEGOLLA, M.; SANT’ANNA, L.M. Por que planejar? Como planejar? currículo - área - aula: escola em debate. 12. ed. Petrópolis: Vozes, 2002.
}

Bibl. Esc. em R., Ribeirão Preto, v. 4, n. 1, p. 37-54, 2015. 
João Melo Maricato, Andrea Pereira Santos e Raidan Cruz Silveira

A identificação dos planos de ensino deu-se por meio dos sites das universidades e, caso não estivessem disponíveis, foram solicitadas por e-mail aos coordenadores dos cursos. Nos casos em que as informações não foram disponibilizadas nos sites ou por e-mail, solicitaram-se tais informações via Sistema de Informações ao Cidadão (SIC). As solicitações foram realizadas entre os meses de abril a novembro de 2012.

Após a coleta e organização dos dados, identificou-se o total 655 referências citadas nos planos de ensino do conjunto de universidades participantes. Diante de problemas identificados na elaboração das referências, no caso das obras organizadas (coletâneas de artigos), considerou-se para fins de análise, o organizador como "autor".

Após a construção e análise destes indicadores, foi investigada a ocorrência da temática biblioteca escolar nas 19 obras mais influentes (mais citadas nos planos de ensino dos cursos). Isso foi realizado através da análise dos sumários e índices dessas obras, bem como, extensa leitura técnica das mesmas.

\section{Resultados e Discussões: Disciplinas de Didática}

Foram identificadas 13 nomenclaturas de disciplinas ligadas à didática no conjunto de universidades e cursos. "Didática" é a mais usual entre todas as nomenclaturas, sendo utilizada 17 vezes (aproximadamente 59\% do total). Em alguns cursos de pedagogia das universidades participantes, a disciplina Didática aparece combinada a outras. Isso mostra a importância da disciplina nos referidos cursos. A nomenclatura "Didática I e II" aparece, na sequência, com maior frequência nos documentos pesquisados (8 e 5 respectivamente).

A UNIFAL-MG foi a que mais apresentou disciplinas relacionadas à didática, 2 no total. As disciplinas são: Didática, Organização didática da educação infantil I e II. É possível deduzir, a partir dos dados, que o curso de pedagogia dessa universidade possui maior preocupação em trabalhar a didática de maneira geral e, em específico na educação infantil, uma vez que dispõe de duas disciplinas para esse fim. Teoricamente, existe maior possibilidade de que esse curso abarque conteúdos sobre biblioteca escolar.

No grupo dos cursos que possuem duas disciplinas relacionadas à didática, fazem parte as universidades: UFC, UFFS, UFGD, UFMS, UFPA, UNIRIO, UFMA, UFMT, UFRR, FURG e UFSC, sendo que as 5 últimas possuem as mesmas disciplinas (Didática I e II). 
As disciplinas de didática em cursos de pedagogia no Brasil e a ocorrência da temática biblioteca escolar: um estudo bibliométrico das influências bibliográficas

Pode-se esperar que essas 5 universidades contemplem uma visão mais ampla e trabalhada no que se refere as formas de compreensão das relações de ensino-aprendizagem aos alunos (justifica-se pela extensão da disciplina Didática em I e II). Isso condiz com o postulado pelo autor Libâneo ao conceituar um dos objetivos da didática: "proporcionar aos alunos os meios para que assimilem ativamente os conhecimentos" (LIBÂNEO, 2008, p. 54).

As seis universidades restantes explicitadas no parágrafo anterior possuem a combinação da disciplina Didática com outra disciplina específica. A UFC dispõe da disciplina Didática e a disciplina Didática I. A UFFS contempla a Didática e a Didática geral. A UFGD inclui a Didática e os Fundamentos em didática. Já a UFMS e a UFPA possuem respectivamente as disciplinas Didática e Didática e relações pedagógicas e, Didática e Didática e a prática pedagógica no ensino fundamental. Há uma pequena variação na abordagem dessas duas últimas. Elas enfatizam as relações e a prática pedagógica. Tendo como pressuposto a revisão de literatura da pesquisa que discorre sobre a biblioteca escolar como instrumento pedagógico, também existe uma grande possibilidade da existência da temática biblioteca escolar nas bibliografias dessas disciplinas. Entretanto, como já citado, a biblioteca deve ser vista como um espaço onde essas práticas de ensino possam ser efetivadas. Finalmente, a UNIRIO, que conta com as disciplinas Didática e Didática: questões contemporâneas.

\section{$\underline{\text { Tipos de documentos citados nas bibliografias das Disciplinas de Didática }}$}

O estudo em questão reuniu 655 citações, sendo que essas citações se resumiram em 8 tipos de documentos. Os materiais variaram entre artigos de revistas, artigos de eventos científicos, decretos, documentos normativos, dissertações de mestrado, teses de doutorado, notas de aula, livros (Gráfico 1). 
João Melo Maricato, Andrea Pereira Santos e Raidan Cruz Silveira

\section{Gráfico 1 - Tipos de documentos citados nas disciplinas de didática dos cursos de pedagogia no Brasil}

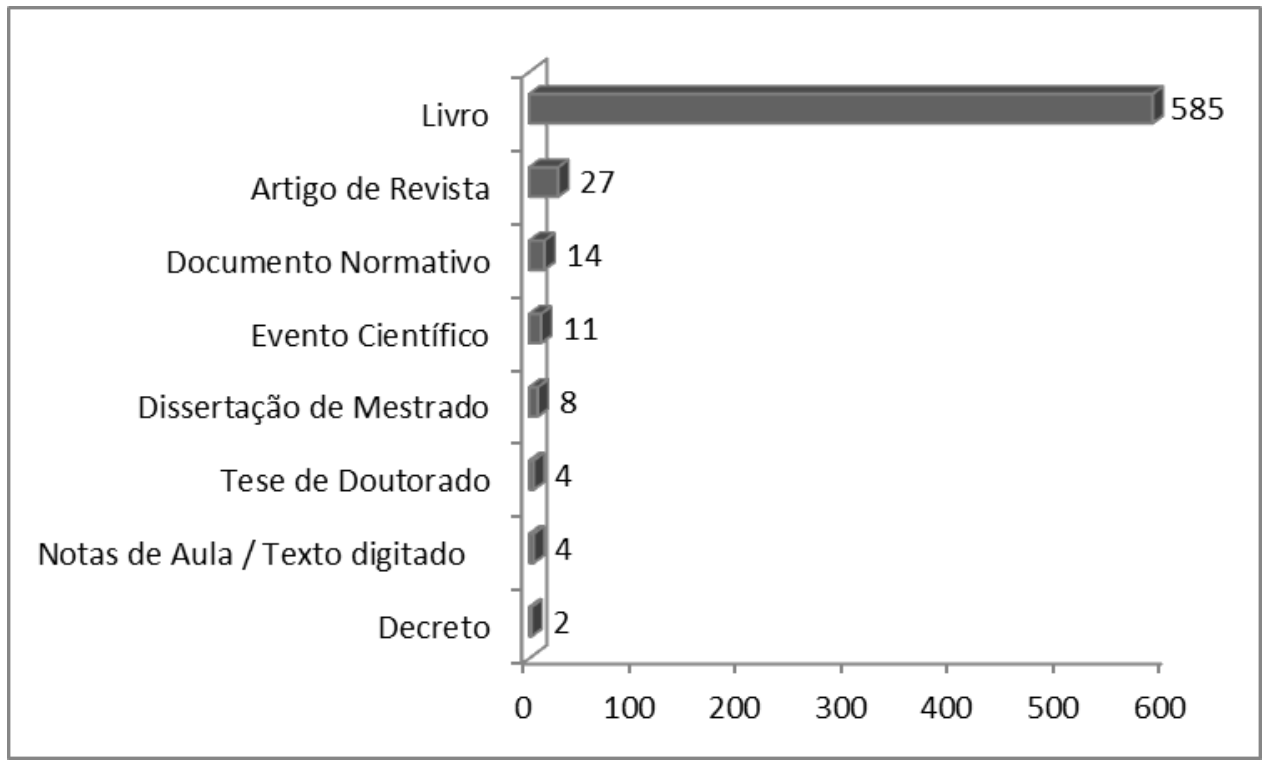

Fonte: Dados da pesquisa coletados em 2012

Dos documentos que tiveram o maior número de ocorrência, os livros merecem destaque. Das 655 citações, 585 publicações foram para livros (quase 90\% do total). Foi possível identificar, ainda, que os livros se dividiram entre obras de única autoria (autor pessoal e entidade), obras com autoria coletiva e obras organizadas - onde uma pessoa se propõe a organizar textos de diversos autores, inclusive os próprios. Alguns estudos (COSTA; VANS, 2010), que também analisaram a tipologia dos documentos, porém com outras perspectivas, também identificaram livros e capítulos de livros como as principais fontes citadas.

Na segunda posição estão os artigos oriundos de revistas científicas (eletrônicas, em sua maioria), com 27 ocorrências. Os documentos governamentais, de caráter normativo, representaram a terceira colocação, com 14 citações, seguida pelos eventos científicos, com 11 citações. Dissertação de mestrado (8), Notas de aula (4) Tese de doutorado (4), e, Decreto (2) completam a lista de tipos de documentos mais citados.

Em se tratando de artigos publicados em revistas, identificou-se apenas 27 citações. É um número consideravelmente baixo se levarmos em consideração o rico conteúdo que pode ser encontrado em um artigo. A qualidade das revistas também é um fator a ser considerado, pois, dependendo da revista em que se deseja publicar, a produção científica passa por níveis rigorosos de avaliação. 
As disciplinas de didática em cursos de pedagogia no Brasil e a ocorrência da temática biblioteca escolar: um estudo bibliométrico das influências bibliográficas

Ainda sobre os tipos de documentos citados, o Gráfico 2 demonstra os tipos de documentos por universidade participante:

\section{Gráfico 2 - Tipos de documentos, por universidade, citados nas disciplinas de didática} dos cursos de pedagogia no Brasil

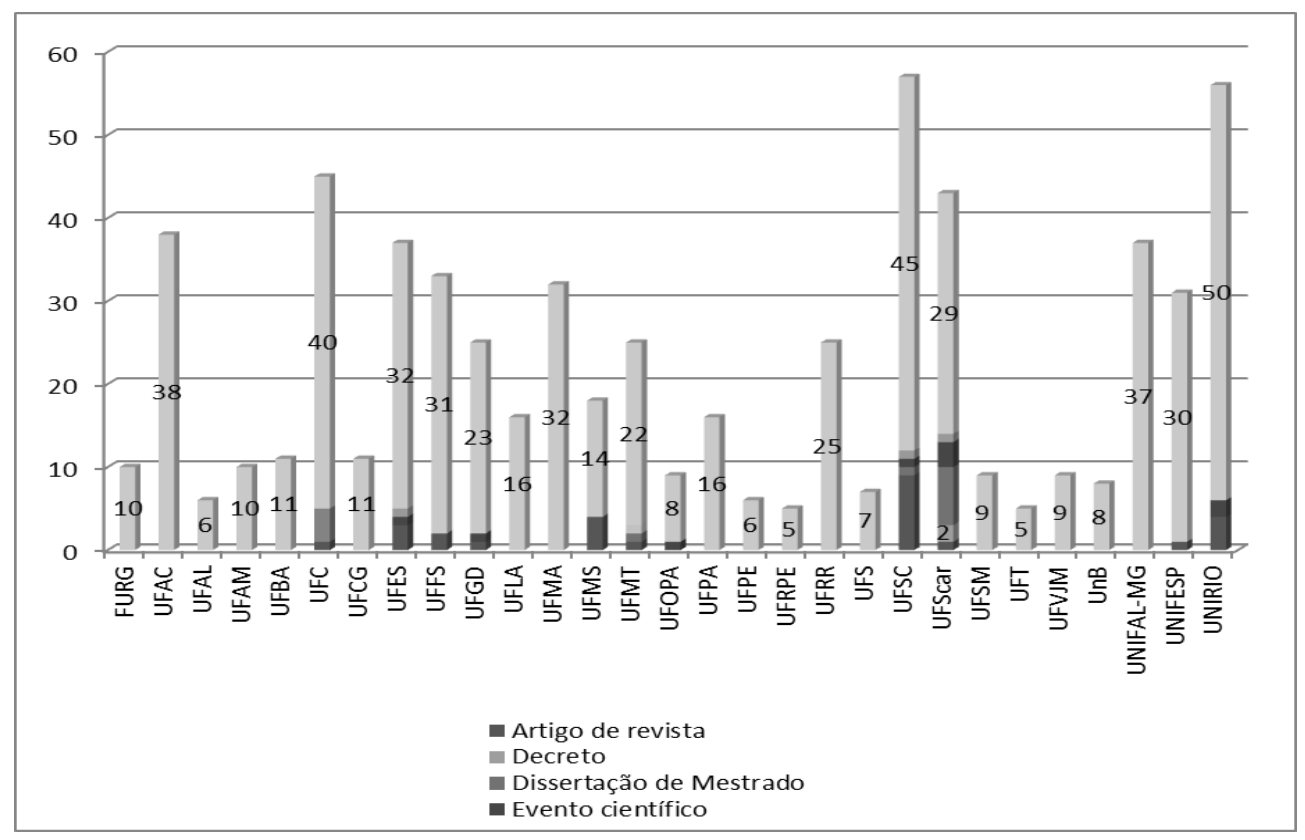

Fonte: Dados da pesquisa coletados em 2012

Das universidades que mais citaram o livro como referência, a UNIRIO está em primeiro lugar, com 50 citações. Em segundo está a UFSC com 45 citações de livros, em terceiro a UFC, com 40 citações, seguidas da UFAC com 38 e UNIFAL-MG com 37. É interessante salientar que dessas 5 universidades citadas, a UFAC indica o livro como único material de referência. Em um trabalho realizado pela Coordenação de Aperfeiçoamento de Pessoal de Nível Superior - CAPES (1978, p. $6^{2}$ apud BRAMBILLA; STUMPF, 2006, p. 42) os autores compartilham a preocupação da ênfase dada ao livro como única fonte de informação e material didático. Segundo eles, é necessário colocar ao alcance do estudante/leitor outros meios informacionais, independentemente de sua forma, no intuito de motivar um uso mais frequente de fontes alternativas. Das universidades analisadas, a UFSCar é a que mais se preocupa em trazer múltiplos documentos informacionais, são 7 tipos diferentes no total.

\footnotetext{
${ }^{2}$ COORDENAÇÃO DE APERFEIÇOAMENTO DE PESSOAL DE NÍVEL SUPERIOR. O ensino de Biblioteconomia no Brasil. Brasília: CAPES, 1978. v.3: Análise da literatura recomendada no ensino de Biblioteconomia no Brasil.
} 
Autores Citados nas Disciplinas de Didática

O estudo sobre autores identificou 304 citações, as quais podem ser divididas em autoria individual, coletiva ou organização (Tabela 1).

Tabela 1 - Autores citados nas disciplinas de didática

\begin{tabular}{|c|c|c|}
\hline Autor & Universidades citantes & Total de citações \\
\hline LIBÂNEO, J. C. & 22 & 31 \\
\hline CANDAU, V. M. & 19 & 31 \\
\hline VEIGA, I. P. A. & 18 & 42 \\
\hline FREIRE, P. & 14 & 21 \\
\hline PIMENTA, S. G. & 13 & 24 \\
\hline GIMENO SACRISTÁN, J. & 12 & 20 \\
\hline ZABALA, A. & 12 & 16 \\
\hline PÉREZ GÓMEZ, A. I. & 10 & 13 \\
\hline OLIVEIRA, M. R. N. S. & 10 & 12 \\
\hline VASCONCELLOS, C. S. & 9 & 16 \\
\hline CASTRO, A. D. & 8 & 10 \\
\hline HAIDT, R. C. C. & 8 & 10 \\
\hline ANDRE, M. E. D. A. & 8 & 8 \\
\hline MIZUKAMI, M. G. N. & 8 & 8 \\
\hline LUCKESI, C. C. & 7 & 12 \\
\hline HOFFMANN, J. & 7 & 11 \\
\hline MINISTÉRIO DA EDUCAÇÃO & 6 & 12 \\
\hline CARVALHO, A. M. P. & 6 & 8 \\
\hline ESTEBAN, M. T. & 6 & 8 \\
\hline FAZENDA, I. & 6 & 8 \\
\hline SAVIANI, D. & 6 & 7 \\
\hline TARDIF, M. & 6 & 7 \\
\hline COMENIUS & 6 & 6 \\
\hline NÓVOA, A. & 6 & 6 \\
\hline CORDEIRO, J. & 5 & 8 \\
\hline HERNÁNDEZ, F. & 5 & 8 \\
\hline FREITAS, L. C. & 5 & 6 \\
\hline PERRENOUD, $\mathrm{P}$. & 4 & 7 \\
\hline FELTRAN, A. & 4 & 6 \\
\hline LOPES, O. A. & 4 & 6 \\
\hline VENTURA, M. & 4 & 6 \\
\hline GASPARIN, J. L. & 4 & 5 \\
\hline MASETTO, M. & 4 & 5 \\
\hline SILVA, T. T. & 4 & 5 \\
\hline BRANDÃO, C. R. & 4 & 4 \\
\hline GADOTTI, M. & 4 & 4 \\
\hline GHIRALDELLI JÚNIOR, P. & 4 & 4 \\
\hline MOREIRA, A. F. B. & 4 & 4 \\
\hline
\end{tabular}

Fonte: Dados da pesquisa coletados em 2012 
As disciplinas de didática em cursos de pedagogia no Brasil e a ocorrência da temática biblioteca escolar: um estudo bibliométrico das influências bibliográficas

A autora VEIGA, I. P. A (Citamos somente a autoria sem colocar a data, pois as obras identificadas são referenciadas em datas diferentes), foi a que mais recebeu citações na literatura correspondente à didática. Suas obras tiveram 42 citações. Porém, algumas obras são fruto de livros organizados por VEIGA (citada em diferentes datas), e não autora propriamente dita.

Na sequência, figuram os autores CANDAU e LIBÂNEO (citados em diferentes datas), como os mais citados, ambos com 31 citações. Completando os 5 autores mais citados estão PIMENTA (citada em diferentes datas), com 24 citações e FREIRE (citada em diferentes datas) com 21.

A tabela 1 traz o quantitativo dos autores mais citados (no mínimo 4) nos planos de ensino dos cursos de pedagogia das universidades advindo da contagem de autor por universidade participante (número de universidades que citaram o autor) e total de citações (considerando o número de vezes que o autor foi citado). Assim, a representação dos números equivale à quantidade de ocorrência única por universidades, e, também, o quantitativo de vezes que foi citado (um mesmo plano de ensino pode citar diferentes obras de um mesmo autor). O quadro 1 pretende medir a influência de cada autor em relação ao total de universidades. Quanto mais universidades o autor tiver sido citado, maior é a relação de influência em relação ao total de universidades participantes.

A tabela 1 apresenta LIBÂNEO (citado em diferentes datas) (Professor Titular aposentado da Universidade Federal de Goiás. Disponível em: http://buscatextual.cnpq.br/. Acesso em: 3 fev. 2013.) como o autor mais influente das universidades participantes. $\mathrm{Na}$ contagem, o autor foi citado em 22 das 29 universidades participantes da pesquisa. Nesse sentido, LIBÂNEO teve pelo menos uma citação em alguma das disciplinas de didática dessas universidades, o que significa que ele é o autor que mais mantém relações de citações/universidade. Em segundo lugar está CANDAU (Professora titular da Pontifícia Universidade Católica do Rio de Janeiro. Disponível em: http://buscatextual.cnpq.br/ Acesso em: 3 fev. 2013), com 19 aparições únicas. Em terceiro lugar aparece VEIGA (Professora Titular Emérita e pesquisadora associada sênior da Universidade de Brasília. Disponível em: http://buscatextual.cnpq.br/. Acesso em: 04 fev. 2013.), com 18. Essa última apresentou uma queda considerável nesse novo critério de análise. Isso significa que, apesar de bem atuante no quantitativo geral, ela não é a autora predominante no conjunto de universidades. Isso 
permite concluir que sua relação de influência entre às universidades não é a maior como os dados iniciais indicavam.

Obras citadas e Influentes nas Disciplinas de Didática

Em se tratando das obras, foram identificadas o total de 354 diferentes. A obra "Didática" (LIBÂNEO) obteve 20 citações. Na segunda posição aparece a obra "A didática em questão" (CANDAU), com 14 citações. As três obras “A prática educativa: como ensinar" (ZABALA), "Compreender e transformar o ensino" (GIMENO SACRISTÁN; PÉREZ GÓMEZ) e "Repensando a didática" (VEIGA), com 13 ocorrências cada uma.

Em se tratando das obras mais influentes nas universidades, o quadro 1 apresenta a contagem de citações por universidade (em, no mínimo, 4 universidades diferentes).

\section{Quadro 1 - Obras mais citadas pelas universidades nos planos de ensino nas disciplinas de didática dos cursos de pedagogia no Brasil}

\begin{tabular}{|l|c|}
\hline \multicolumn{1}{|c|}{ Obras } & $\begin{array}{c}\text { Universidades } \\
\text { citantes }\end{array}$ \\
\hline Didática (Indicação de responsabilidade: LIBÂANEO, J. C.) & 18 \\
\hline A didática em questão & 13 \\
\hline A prática educativa: como ensinar & 11 \\
\hline Compreender e transformar o ensino & 10 \\
\hline Repensando a didática & 10 \\
\hline Pedagogia da autonomia: saberes necessários à prática educativa & 8 \\
\hline Didática: o ensino e suas relações & 8 \\
\hline Ensino: as abordagens do processo & 8 \\
\hline Didática e formação de professores: percursos e perspectivas no Brasil e em & 7 \\
\hline Portugal & 7 \\
\hline Curso de didática geral & 7 \\
\hline Rumo a uma nova didática & 6 \\
\hline Ensinar a ensinar: didática para a escola fundamental e média & 6 \\
\hline Democratização da escola pública: a pedagogia crítico-social dos conteúdos & 6 \\
\hline Escola e democracia & 6 \\
\hline Planejamento: projeto de ensino-aprendizagem e Projeto Político Pedagógico & 6 \\
\hline Saberes docentes e formação profissional & 5 \\
\hline Didática (Indicação de responsabilidade: CORDEIRO, J) & 5 \\
\hline Avaliação da aprendizagem escolar & 5 \\
\hline Didática e interdisciplinaridade & 5 \\
\hline Alternativas no ensino de didática & 5 \\
\hline Avaliação: uma prática em busca de novos sentidos & 5 \\
\hline Didática, currículo e saberes escolares & \\
\hline
\end{tabular}

Bibl. Esc. em R., Ribeirão Preto, v. 4, n. 1, p. 37-54, 2015. 
As disciplinas de didática em cursos de pedagogia no Brasil e a ocorrência da temática biblioteca escolar: um estudo bibliométrico das influências bibliográficas

\begin{tabular}{|l|c|}
\hline Saberes pedagógicos e atividade docente & 5 \\
\hline A organização do currículo por projetos de trabalho & 4 \\
\hline Parâmetros Curriculares Nacionais & 4 \\
\hline Técnicas de ensino: por que não? & 4 \\
\hline Didática magna & 4 \\
\hline Lições de didática & 4 \\
\hline Uma didática para a pedagogia histórico-crítica & 4 \\
\hline
\end{tabular}

Fonte: Dados da pesquisa coletados em 2012

É interessante salientar que das 354 obras, 275 obras foram citadas uma única vez por uma das universidades. Assim sendo, 79 tiveram seus nomes citados em mais de 1 universidade participante.

A obra "Didática" de LIBÂNEO obteve pelo menos 1 citação em 18 universidades diferentes, sendo considerada a obra central. Isso evidencia a importância da obra para as disciplinas de didática, podendo ser considerada uma obra de referência. Além disso, é a obra mais influente nas universidades. Essa obra traz uma apresentação teórica das práticas didáticas, sendo que seus principais assuntos estão ligados à: "Prática educativa, pedagogia e Didática", "Didática e democratização do ensino", "Didática: teoria da instrução e do ensino", "O processo de ensino na escola", "O processo de ensino e o estudo ativo", "Os objetos e conteúdos de ensino", "Os métodos de ensino", “A aula como forma de organização do ensino", “A avaliação escolar", “O planejamento escolar” e "Relações professor-aluno na sala de aula".

$\mathrm{Na}$ segunda posição está a obra organizada "A didática em questão" (CANDAU), citada em 13 universidades diferentes. A obra, que contém um conjunto de textos organizados por Candau, está dividida em: "Papel da didática na formação de educadores"; "Pressupostos teóricos do ensino de didática"; "Abordagens alternativas para o ensino da didática"; "A pesquisa em didática - realidade e propostas".

Em terceiro lugar está a obra "A prática educativa: como ensinar” (ZABALA), com 11 aparições. O sumário dessa obra contempla assuntos: “A prática educativa: unidades de análise"; "A função social do ensino e a concepção sobre os processos de aprendizagem: instrumentos de análises"; "As sequências didáticas e as sequências de conteúdo"; "As relações interativas em sala de aula: o papel dos professores e dos alunos"; "A organização social da classe"; "A organização dos conteúdos"; "Os materiais curriculares e outros recursos didáticos"; "A avaliação". 
As obras "Compreender e transformar o ensino" (GIMENO SACRISTÁN; PÉREZ GÓMEZ) e "Repensando a didática" (VEIGA), aparecem nas próximas colocações, ambas com 10 ocorrências. A primeira é uma obra com autoria dupla, dividida entre os capítulos: “As funções sociais da escola: da reprodução à reconstrução crítica do conhecimento e da experiência; Os processos de ensino-aprendizagem: análise didática das principais teorias da aprendizagem; Aprendizagem escolar: da didática operatória à reconstrução da cultura na sala de aula; Ensino para compreensão; Compreender o ensino na escola: modelos metodológicos de investigação educativa; A função e formação do professor/a no ensino para a compreensão: diferentes perspectivas (textos de PÉREZ GÓMEZ)”; "O currículo: os conteúdos do ensino ou uma análise da prática?; O que são os conteúdos de ensino?; Plano do currículo, plano de ensino: o papel dos professores/as; Âmbitos do plano; A avaliação no ensino (textos de GIMENO SACRISTÁN).

Já a segunda obra "Repensando a didática" de (VEIGA), compreende vários textos organizados em: "Didática e ensino: relações e pressupostos (Olga Teixeira Damis)"; "Didática: uma retrospectiva histórica (Ilma Passos Alencastro Veiga)"; "Planejamento do ensino numa perspectiva crítica de educação (Antonia Osima Lopes)"; “Os objetivos da educação (Maria Eugênia Lima e Montes Castanho)"; "Conteúdos escolares: a quem compete a seleção e a organização? (Pura Lúcia Oliver Martins)"; "Metodologia do ensino: cultura no caminho contextualizado (Oswaldo Alonso Rays)"; "Na dinâmica interna da sala de aula: o livro didático (Maria Bernadete Santos Cecília Caporalini)"; "Repensando a avaliação da aprendizagem (Vani Moreira Kenski)" e "A relação professor-aluno (Maria Isabel da Cunha)".

\section{$\underline{\text { A Temática Biblioteca Escolar nas Bibliografias das Disciplinas de Didática }}$}

Terminada a etapa de caracterização das disciplinas de didática dos cursos de pedagogia, o presente tópico busca compreender ocorrência da temática biblioteca escolar nas 19 obras mais influentes/citadas nos planos de ensino das universidades analisadas.

Constatamos que nenhuma das 19 obras analisadas possui a ocorrência do termo biblioteca escolar nos seus índices e sumários. Isso nos permite afirmar que a discussão sobre biblioteca escolar no contexto da disciplina não figuram como assunto primário. Em estudo semelhante, onde também se analisou os livros de didática, porém num outro ponto de vista, o 
As disciplinas de didática em cursos de pedagogia no Brasil e a ocorrência da temática biblioteca escolar: um estudo bibliométrico das influências bibliográficas

autor Silva (1991³ apud MACEDO, 2005, p. 174) "chama a atenção o fato de que apenas um autor, da área de didática, profetiza a biblioteca escolar (e ainda indiretamente) como recurso de ensino-aprendizagem".

Com a leitura técnica das obras, foi possível verificar que poucos são os autores que citam a biblioteca escolar, ou mesmo biblioteca em suas obras. Mesmo aqueles que citam, não apresentam uma discussão interessada sobre assunto. Fatalmente, o tema raramente é tratado nas obras e, quando ocorre, a abordagem é superficial e secundária.

A obra Didática (LIBÂNEO, 2003), que é a mais influente, em nenhum dos seus 11 capítulos menciona o tema biblioteca ou biblioteca escolar. No texto, a única citação do termo biblioteca identificada remete-a a um recurso para a busca de informações:

Cada disciplina exige também seu material específico, como ilustrações e gravuras, filmes, mapas e globo terrestre, discos e fitas, livros, enciclopédias, dicionários, revistas, álbum seriado, cartazes, gráficos, etc. Alguns autores classificam ainda, como meios de ensino, manuais e livros didáticos; rádio, cinema, televisão; recursos naturais (objetos e fenômenos da natureza); recursos da localidade (biblioteca, museu, indústria, etc.) [...] (LIBÂNEO, 2003, p. 173, grifo nosso)

É visível que a citação nem chega a expressar o termo biblioteca escolar. $\mathrm{O}$ autor apenas faz menção ao termo biblioteca como uma possibilidade de meio de ensino. Estranha o fato de que o livro em questão faz menções sobre a forma como o professor deve despertar no aluno a curiosidade de ser autônomo, buscar o conhecimento fora da sala.

O ensino, assim, é uma combinação adequada entre a condução do processo de ensino pelo professor e a assimilação ativa como atividade autônoma e independente do aluno. Em outras palavras, o processo de ensino é uma atividade de mediação pela qual são providas as condições e os meios para os alunos se tornarem sujeitos ativos na assimilação de conhecimentos (LIBÂNEO, 2003, p. 89)

Porém, na grande maioria dos trechos do livro, as relações de ensino-aprendizagem se dão dentro da sala de aula. Isso é uma constante na grande maioria das obras analisadas.

\footnotetext{
${ }^{3}$ SILVA, W. C. Miséria da biblioteca escolar. São Paulo: Cortez, 1991.

Bibl. Esc. em R., Ribeirão Preto, v. 4, n. 1, p. 37-54, 2015.
} 
João Melo Maricato, Andrea Pereira Santos e Raidan Cruz Silveira

Outra obra que também remete a ideia do professor como agente incentivador do aluno na busca de meios para a concretização do ensino adquirido em sala está presente na obra "Ensino: as abordagens do processo" (MIZUKAMI, 2003).

Cabe ao professor evitar rotina, fixação de respostas e hábitos. Deve simplesmente propor problemas aos alunos, sem ensinar-lhes as soluções. Sua função consiste em provocar desequilíbrios, fazer desafios. Deve orientar o aluno e conceder-lhe ampla margem de autocontrole e autonomia. (MIZUKAMI, 2003, p. 77)

Já a obra "A prática educativa: como ensinar" do autor Zabala, faz uma citação sugerindo o uso da biblioteca na escola, mas deixa claro que o espaço é secundário. "Para oferecer aos alunos os livros que possam dar respostas às pesquisas bibliográficas será indispensável dispor uma boa biblioteca na sala ou, na sua falta, na escola" (ZABALA, 1998, p. 173).

Fica evidente, na visão do autor, que a sala de aula é o primeiro lugar onde a informação bibliográfica deve ser disponibilizada. É interessante pensar na ideia de que a sala de aula compreende um espaço dinâmico entre o ensino e o material a ser pesquisado. No entanto, entende-se que a biblioteca deve representar um espaço privilegiado na escola.

A obra onde se identificou maior ocorrência do termo biblioteca escolar foi "Curso de didática geral" (HAYDT, 2000), ao remeter ao movimento Freinet. Em uma das citações do autor para Freinet, afirma-se que a biblioteca escolar é conhecida como o local de busca de informações e de utilização dos recursos audiovisuais. "Freinet sugere também a projeção de filmes e propõe a utilização da biblioteca escolar, que denomina de 'biblioteca do trabalho', para consulta e pesquisa" (HAYDT, 2000, p. 221). A obra em questão indica, de forma direta no sumário, a utilização de meios denominados procedimentos de ensino, dentre os quais cita: O uso de jogos, dramatização e trabalho em grupo. Além disso, apresenta os recursos audiovisuais e de informática como cabíveis nas relações de ensino. Espanta a não ocorrência do termo biblioteca escolar no sumário dessa obra diante desse contexto, pois a biblioteca escolar, bem estruturada, é um local que engloba não somente os livros, mas, também, a maioria dos recursos e práticas citadas no sumário dessa obra como procedimentos de ensino.

Outra obra que também exprime a ideia de uso da biblioteca é a obra "A organização do currículo por projetos de trabalho" (HERNÁNDEZ; VENTURA, 1998). No sumário da obra há um sub-tópico que apresenta "a busca das fontes de informação". Após a exploração 
As disciplinas de didática em cursos de pedagogia no Brasil e a ocorrência da temática biblioteca escolar: um estudo bibliométrico das influências bibliográficas

do conteúdo, foi possível identificar que o autor traz uma citação do termo biblioteca. "[...] Transformar a biblioteca numa sala de recursos do qual o aluno se valia cada vez que necessitava buscar informação em torno de um tema" (HERNÁNDEZ; VENTURA, 1998, p. 76). A obra traz em si a experiência profissional tida na Escola Pompeu Fabra, de Barcelona que expõe os problemas dos alunos no contexto da sala de aula. Talvez essa seja a obra com uma citação direta que "melhor" traduz a ideia de biblioteca como meio para a busca da informação desejada. Porém, não há nenhuma reflexão posterior sobre o assunto.

Na obra de Luckesi (1999) “Avaliação da aprendizagem escolar" não foi possível identificar através da leitura técnica nenhuma expressão correspondente a biblioteca escolar. A obra traz uma perspectiva histórico/social da didática através de vários tópicos. Alguns deles apontam meios para o desenvolvimento do educando, mas sempre com um olhar do professor (progenitor do ensino) na sala em aula.

É quase unânime a ocorrência da temática avaliação nos processos didáticos abordados pelos autores das obras analisadas. Isso é um grande indício de que os processos didáticos referidos nas obras precisam passar por constantes avaliações. Outra predominância já citada é a ideia de que a sala de aula é a principal, quase exclusiva, genitora do ensino no contexto escolar do aluno.

Levando em consideração a citação de Silva (1991³ apud MACEDO, 2005, p. 174) a respeito do desuso da biblioteca escolar por parte dos autores da área de didática, é possível evidenciar um forte indício de que a realidade vivida na época é a quase idêntica a de hoje. A análise em questão apresenta um panorama similar ao estudo de SILVA $\left(1991^{3}\right.$ apud MACEDO, 2005) e evidencia a ausência da temática biblioteca escolar como ferramenta pedagógica nas práticas de ensino dos cursos de Pedagogia analisados. 


\section{Considerações finais}

O estudo em questão teve como objetivo geral, caracterizar as bibliográficas (básicas e complementares) apresentadas nos planos de ensino das disciplinas de didática em cursos de pedagogia no Brasil e a abordagem da temática biblioteca escolar nesse contexto.

Identificaram-se os autores e obras mais citados nas disciplinas de didática dos cursos de pedagogia no Brasil, sendo possível conhecer quais autores estão influenciando a formação dos pedagogos no Brasil.

Após as etapas de caracterização das disciplinas de didática, buscou-se compreender a existência da temática biblioteca escolar nas disciplinas. Para isso, analisaram-se os sumários e índices das obras, bem como, realizou-se a leitura técnica desses livros.

Constatamos por meio da análise das 19 obras mais influentes, que nenhuma apresentou em seus sumários e índices a temática biblioteca escolar. Com a leitura técnica do conteúdo, foi possível identificar algumas situações onde os autores apresentam a biblioteca como recurso de busca informacional. Porém, quando ocorrem, são aparições breves que não ultrapassam citações descomprometidas em discutir a biblioteca nas relações de ensinoaprendizagem. Em nenhum momento a biblioteca escolar é citada como instrumento pedagógico nas práticas de aprendizagem. Apesar de não ter sido analisado todas as obras identificadas no estudo, o resultado dessa amostragem das obras centrais evidencia uma baixa visão da importância da biblioteca escolar nas relações de ensino-aprendizagem.

A partir do exposto, considera-se que a experiência de pesquisa nas bibliografias das disciplinas de didática, a partir de uma análise bibliométrica das referências, foi de grande valor no que se refere à descoberta e sistematização de conhecimentos. Além disso, foi possível compreender as características das disciplinas de didática e a temática biblioteca escolar nesse contexto.

Observou-se que não existem discussões relacionadas à possibilidade de aplicação do ambiente biblioteca escolar nas práticas pedagógicas de ensino-aprendizagem envolvendo o aluno o professor e bibliotecário. Pode-se afirmar que a compreensão da biblioteca escolar como instrumento pedagógico não está concreta para os estudiosos da área de didática. Porém, é relevante reafirmar o potencial pedagógico da biblioteca escolar na trajetória escolar do aluno, principalmente àqueles inseridos nas séries iniciais. Além do mais, o professor, 
As disciplinas de didática em cursos de pedagogia no Brasil e a ocorrência da temática biblioteca escolar: um estudo bibliométrico das influências bibliográficas

como figura que potencializa a aquisição do conhecimento pelo aluno, precisa conhecer os diversos meios para busca da informação.

Sabe-se que o presente estudo se limita em apresentar apenas a realidade das disciplinas de didática de cursos de pedagogia em algumas universidades federais. Entretanto, o estudo abre oportunidades para diferentes estudos que se interessem em analisar a temática biblioteca escolar em outros contextos, como, por exemplo, em outras disciplinas dos cursos de pedagogia ou outras disciplinas de licenciatura.

\section{Referências}

BRAMBILLA, S. D. S.; STUMPF, I. R. C. Planos de ensino do curso de Biblioteconomia da Universidade Federal do Rio Grande do Sul: estudo bibliométrico de referências. Transinformação, Campinas, v. 18, n.1, jan./abr. 2006. Disponível em: <http://www.brapci.ufpr.br/download.php?dd0=5621 > . Acesso em: 06 ago. 2012.

BUFREM, L.; PRATES, Y. O saber científico registrado e as práticas de mensuração da informação. Ciência da Informação, Brasília, v. 34, n. 2, p. 9-25, maio/ago. 2005. Disponível em: 〈http://www.scielo.br/pdf/ci/v34n2/28551〉. Acesso em: 15 set. 2012.

COSTA, J. G.; VANZ, S. A. S. A produção intelectual em Ciência da Informação: análise de citações do DCI/UFRGS de 2000 a 2008. Em Questão, Porto Alegre, v. 16, n. 1, p. 79-93, jan./jun. 2010. Disponível em: <http://seer.ufrgs.br/EmQuestao/article/view/12921>. Acesso em: 17 jan. 2013.

HAYDT, R. C. C. Curso de didática geral. 7. ed. São Paulo: Ática, 2000. 327 p.

HERNANDEZ, F.; Ventura, M. A organização do currículo por projetos de trabalho. São Paulo: Artmed, 1998

LIBÂNEO, J. C. Didática. São Paulo: Cortez, 2003. São Paulo: Cortez, 2008, 263 p.

LUCKESI, C. Avaliação da aprendizagem escolar. 9. ed. São Paulo: Cortez, 1999.

MACEDO, N. D. (Org.). Biblioteca escolar brasileira em debate: da memória profissional a um fórum virtual. São Paulo: SENAC, 2005.

MIZUKAMI, M. G. N. Ensino: as abordagens do processo. São Paulo: E.P.U., 2003.

ZABALA, A. A prática educativa: como ensinar. Porto Alegre: ARTMED, 1998. 